\title{
Teaching Exploration and Practice of FPGA Course
}

\author{
Guohai Xiong \\ College of Electrical Engineering \& New Energy, China \\ Three Gorges University, Yichang 443002, China \\ xiongguohai@126.com \\ Xinyun Liu \\ Hubei Three Gorges Vocational and Technical College, \\ Yichang 443000, China
}

\begin{abstract}
The FPGA technology becomes an electronic engineering gradually, which controls the field where technology is often use. In order to satisfy the requirement of employment, a lot of colleges and universities has provided FPGA course. But due to the different professions of each school, employment directions are different, and the requirements of FPGA course are different as well. This paper introduced the teaching situations of FPGA courses in our school, listing problems, and measures according to the actual situation of our school, and the theory combined with the experimental class, paying attention to the students' practical ability, will contribute to cultivating competitive talents of FPGA technology.
\end{abstract}

Keywords-FPGA; SOPC; course; exploration; practice

\section{I .INTRODUCTION}

FPGA(Field Programmable Gate Array) is known as an integrated circuit in the form of semi-custom. Due to the improvement of the technological level of semiconductors, FPGA has been widely spread in the area of digital circuit design. Also, the FPGA integrated circuit is being developed based on some programmable device such as PAL and GAL. More over, this kind of circuit has some characters such as high integration density, powerful functions, short cycle of exploration, low investment, supporting repeatable programming and low energy consumption. On the other hand, the technology of SOPC

(System On a Programmable Chip) is used to put the whole system in a slice of FPGA chip. In other words, accomplish the main logic functions of system by one chip. Since the SOPC has flexible design method, which can be used to tailor, extend or upgrade online, with the cooperation of software and hardware. Apart from this, the exploring difficulties of designing SOPC can be decreased

\author{
Sheng Yang \\ College of Electrical Engineering \& New Energy, China \\ Three Gorges University, Yichang 443002, China
}

by making use of current IP, including hardcore and soft core.

\section{II .OBJECTIVE OF SETTING UP FPGA COURSE}

FPGA technology is not only a part of modern electronic technology, but also a combination of electronic technology and computer technology. FPGA part can be used for designing any digital system according to own thoughts. The design is not limited by some chip. FPGA can be selected in many occasions with speed requirements due to parallel processing. A digital system can be designed through traditional schematic input method or programming method. Current FPGA is provided with NiosII, thereby reinforcing function of control part, and further facilitating design of monolithic system. FPGA technology is becoming a common technology which can be commonly used by technology personnel in the fields of electronic engineering and control field. So setting up the course of FPGA is to meet the requirement of market, and many universities have already brought this course into the education of undergraduate and postgraduate students in electrical areas. Knowledge of electronic technical foundation and computer should be acquired for learning the courses. The course is also related to computer language. Our school has set up FPGA courses of electricity major for more than ten years with certain experience. The course also encounters some problems. FPGA course is a course with strong practicality and learning difficulty. Contents are excessive, and class hours are limited. We always think about how to better complete teaching task. 


\section{COURSE CONTENTS}

Courses are divided into two parts of FPGA design and SOPC design. Digital logic circuit and digital system design can be completed by utilizing FPGA in the first part. Objects include sophomore undergraduates. Theoretical courses are combined with experimental courses, which are taught in lab. Students can learn and practice at the same time. A total of 32 credit hours are arranged. Students can know the purpose of FPGA in the first class, and introduce examples of several designs, such as design of taxi meter, traffic light control circuit, signal generator, etc. The equipment can be demonstrated to students, students can obtain certain perceptual knowledge on the course. Learning enthusiasm of students can be fully mobilized, and students can learn with problems. Each lesson is composed of four hours. Students can be assigned with thinking questions related with the class before ending of class. Teacher can question before next class, and the results are included to meantime achievement. Hardware description language explained in the class is VHDL. Students are encouraged to self-learn Verilog. The task can be completed with two hardware description languages. Learning version software and teaching courseware are provided for students. Therefore, we can install the software on computer, which is convenient for learning. FPGA configuration and development software can be briefly introduced aiming at contents of the first 12 credit hours. VHDL parallel sentence, process, signals, variables and sequential sentence are learned. VHDL can be utilized for designing combination circuit and sequential circuits. Students can establish basic concept through designing simple circuit mainly, who can be rapidly familiar with development software and development flow, thereby laying solid foundation for next experiment [1] . Content of next eight credit hours includes the follows: inout port, state machine and element instantiation are designed by utilizing VHDL design. Students can learn FPGA design method and skills in the course of the part. Comprehensive design of 12 credit hours is arranged next. Given topic is design of digital clock. Students also select topic by themselves, such as design of signal generator, DC motor control system, etc. Lower function block is designed with hardware descriptive language, and topic layer is formed by graphic mode, and it is easy to find problem. The design contents of this part are provided for improving comprehensive design ability of students. Since class hours are limited, comprehensive design tasks can be completed in class, and students can bring experimental boards to dormitory, thereby providing students with an environment for testifying own design. Teacher should introduce some graduation design topic for students after comprehensive design acceptance, thereby leading the students to focus on FPGA development.

SOPC is introduced in Part II aiming at graduate and undergraduate students participating in national, provincial electronic contest and SOPC contest. SOPC technology involves several disciplines with certain difficulty in learning. It is required that students have learned FPGA design, including $\mathrm{C}$ language programming ability and knowledge of computer interface. DE2-115 experiment plate of Altera Company is adopted as experiment equipment. SOPC technique is characteristic in FPGA design, powerful advantages of FPGA technology can be shown in 16 class hours. Theory lessons are combined with practice. Teachers should teach and practice at the same time. SOPC technology is briefly introduced and minimum NiosII system is designed in the first eight class hours. Students can be familiar with SOPC technology and DE2-115 development environment as main purpose. Timer design based on SOPC is introduced in the subsequent 8 hours. Self-designed Avalon peripherals and customized NiosII instructions are comprehended. It is regarded as starting stage for learning SOPC technology aiming at deepening understanding on SOPC technology. Since students need to participate in competition, students should complete NiosII sinusoidal signal generator or complete real-time data acquisition system design based on NiosII. Lab report is also an important part of learning. Several excellent reports and several substandard reports are selected for discussion in the classroom; importance of experiment report is stressed. It is regarded as summary of course learning, learned knowledge can be consolidated by seriously completing report, thereby deepening understanding on courses, and preventing plagiarism. Contents of the above two parts are designed aiming at automation, electronics, electrical engineering and automation major. However, FPGA courses of electrical engineering and automation also should be adjusted, which should be set as elective courses.

\section{TRaining OF StUdent Practice AbILITY}

The course of FPGA design does not require separation between theory class and experimental class. Theory class is as important as experiment class due to special feature of the course. Experiment class can allow student to apply related FPGA theory knowledge to practical condition, 
thereby improving their mastering ability on theory and reinforcing understanding on theory [2]. We focus on training students' practical ability, encouraging students to innovate, and lead students to read extracurricular books with question and check some internet information. Experiment quantity should be rationally arranged, thereby trying to obtain some achievement in device during each experiment. Two students can use one computer and one experiment board. Each student is responsible for one part, designed circuit or program name should be inserted into own student number, thereby encouraging students to be different from other students in design. Students with innovation should be praised and given with some scores. Some verification experiments should be arranged at primary stage. It is required that each student should participate in the experiment. Design experiment should be arranged at medium stage, students should participate in design, corresponding work tasks should be completed according to own ability. Advanced experiment refers to several experiments based on NiosII, which should be completed by contest students during spare time. The experiments can be selected according to own interests. Experiments at several grades should be designed, therefore each student can participate in the experiment. Practical ability of each student can be trained. Some experiment can not be completed by one student, two or several students should jointly complete the experiment. Design tasks can be divided into several modules. One student is responsible for several modules, and all modules can be combined into a system after design, thereby increasing students' team awareness, collaboration ability, communication ability, independent thinking and working ability [3]. Student practical ability standards are cultivated based on how to better join with occupation market.

\section{IMPROVEMENT OF TEACHING METHODS AND ENRICHMENT OF TEACHING METHODS}

It is impossible to explain all contents in the classroom due to limited class hours. It is required that important contents should be completely explained in classroom. Students can be led for self-learning, discussion in group or learning in interaction form aiming at some unimportant contents, thereby promoting students to actively think about problem, searching method and approach to solve problem. On-line teaching platform should be established, learning and related technical information can be provided. Message boards can be provided for student and teachers to exchange [4]. Teachers should accept feedback suggestion from students, thereby continuously improving teaching methods. PowerPoint courseware should be produced, and multimedia teaching should be adopted. Class hours can be saved, teaching efficiency can be improved, the method is characterized by intuitive feature, dynamics, graphic, audio and visual coexistence. Students' learning interests can be enhanced. Multimedia, as effective assistant teaching tool, can serve teaching, which should be applied properly. After multimedia teaching is used, its advantages should be mastered properly, thereby leading students some time for thinking, and forming and upgrading new recognition structure [5]. Organic combination between traditional teaching method and multimedia teaching method is also a topic for us.

\section{SCIENTIFIC RESEARCH AND GRADUATION DESIGN}

Both teachers and students should actively participate in research activities in order to teach and learn the course well. Practical problem should be solved with learned knowledge, they also can observe own shortcomings on the contrary, thereby improving own level. Some graduation design topics and contents related to courses can be introduced to students on schedule, thereby students can make clear learning objectives in next stage, and tracing development direction of industry. Content difficulty of participated research topic and introduced graduation design should be controlled well for students, which should not be too difficult.

\section{CONCLUSION}

Design of FPGA technology for designing electronic system is in line with electronic technology development demand, which can improve students' comprehensive ability, and expand career channel. FPGA technology update speed is fast, which requires continuous reform on teaching. Different teaching methods should be adopted according to difficult teaching contents, thereby meeting development demand. We should discuss how to teach and learn the course well.

\section{ACKNOWLEDGEMENT}

This work is supported by the Natural Basic Scientific Research and Application Special Project of Yichang City in China No. A14-302-a20 


\section{REFERENCES}

[1] Wang Yuanyuan, Discussion on the Application and Design of FPGA Practice Teaching and Reform, Research Work of University Laboratory, Vol.3, No9, pp.52-55, 2012.

[2] Yu Nenghui, On Practice and Exploration of FPGA Teaching, Journal of Nanchang Education College, Vol.27, No11, pp.49-50, 2012.

[3] Chen Meihui, Problems and Countermeasures of Electrician and Electronic Technology Experiment Class, Journal of Changchun
University of Technology, Vol.31, No.6, pp.87-88, 2010.

[4] Ma Zhiqiang, etc, Research on Teaching Reform of FPGA Course, China Extramural Education, No8, pp.248-249, 2009.

[5] Fu Yang, Exploring Electrical and Electronic Classroom Teaching and Improving Teaching Quality, Experimental Technology and Management Vol.29, No4, pp.260-271, 2012. 